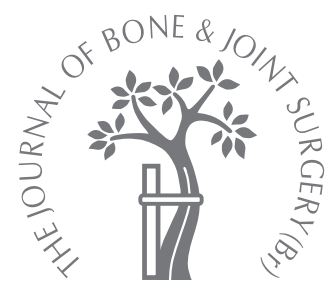

\title{
The impact of pre-operative obesity on weight change and outcome in total knee replacement
}

\author{
A PROSPECTIVE STUDY OF 529 CONSECUTIVE PATIENTS
}

M. M. Dowsey,

D. Liew,

J. D. Stoney,

P. F. Choong

From The University

of Melbourne,

Melbourne, Australia

M. M. Dowsey, RN,

BapplsSci, PhD, Clinical Trials

and Research Coordinator

J. D. Stoney, FRACS,

FAOrthA, Consultant

Orthopaedic Surgeon

P. F. Choong, MD, FRACS,

FAOrthA, Sr Hugh Devine

Professor of Surgery and Head,

Director of Orthopaedics

Department of Orthopaedics

D. Liew, FRACP, PhD,

Physician and Epidemiologist

Department of Medicine

University of Melbourne, Level

4 Clinical Sciences Building, 29

Regents Street, Fitzroy 3065

Melbourne, Victoria, Australia.

Correspondence should be sent to Professor P. F. M. Choong; email: sarcoma@bigpond.net.au

(C)2010 British Editorial Society of Bone and Joint Surgery doi:10.1302/0301-620X.92B4. $23174 \$ 2.00$

$J$ Bone Joint Surg $[\mathrm{Br}]$ 2010;92-B:513-20. Received 28 July 2009; Accepted after revision 10 December 2009

We carried out a prospective, continuous study on 529 patients who underwent primary total knee replacement between January 2006 and December 2007 at a major teaching hospital. The aim was to investigate weight change and the functional and clinical outcome in nonobese and obese groups at 12 months post-operatively. The patients were grouped according to their pre-operative body mass index (BMI) as follows: non-obese (BMI $<30 \mathrm{~kg} / \mathrm{m}^{2}$ ), obese $\left(B M I{ }^{3} 30\right.$ to $39 \mathrm{~kg} / \mathrm{m}^{2}$ ) and morbidly obese $\left(B M I>40 \mathrm{~kg} / \mathrm{m}^{2}\right)$. The clinical outcome data were available for all patients and functional outcome data for 521 (98.5\%). Overall, $318(60.1 \%)$ of the patients were obese or morbidly obese.

At 12 months, a clinically significant weight loss of $\geq 5 \%$ had occurred in 40 (12.6\%) of the obese patients, but 107 (21\%) gained weight. The change in the International Knee Society score was less in obese and morbidly obese compared with non-obese patients $(p=0.016)$. Adverse events occurred in $30(14.2 \%)$ of the non-obese, $59(22.6 \%)$ of the obese and $20(35.1 \%)$ of the morbidly obese patients $(p=0.001)$.

Most patients presenting for total knee replacement (TKR) are obese. ${ }^{1-3}$ Obesity has been linked to a poor outcome after TKR in both the short ${ }^{4}$ and longer term. ${ }^{5}$ However, loss of weight in obese patients awaiting surgery is difficult, partly because the symptoms limit their ability to exercise, and they often believe that joint replacement is crucial for weight loss. Improvements of function and quality of life (QoL) occur within three months of TKR, ${ }^{6-9}$ and thus the perceived barrier to weight loss should be removed at this time. There is, however, little information on the impact of TKR on subsequent weight loss, although it has been suggested that this may not occur after TKR. ${ }^{10,11}$ These studies have been limited in sample size. One review established that two years after TKR $17 \%$ of patients had lost $5 \%$ or more of their preoperative weight. ${ }^{12}$ It would be of clinical value to determine if there is a patient profile in which weight loss or gain can be predicted after primary TKR. This would allow appropriate counselling of those patients who are unlikely to lose weight.

Our study had three aims; firstly, to establish the rate of clinically significant weight change in patients 12 months after primary TKR; secondly, to compare the clinical details and characteristics of patients who lost or gained weight after primary TKR with those who did not and, thirdly, to compare the clinical and functional outcome between obese and non-obese patients after TKR.

\section{Patients and Methods}

This was a prospective, continuous study of patients grouped according to the body mass index (BMI) for comparison of outcome and weight change. The investigation was undertaken at a 460-bed university-affiliated tertiary-referral centre in Melbourne. All patients admitted for primary TKR between January 1, 2006 and December 31, 2007 were eligible for the study. The treatment and rehabilitation protocol was standardised through the use of validated clinical pathways protocols. ${ }^{13}$ This included a daily dose of low molecular weight heparin, antiembolic stockings and mobilisation on the first post-operative day. A diagnosis of deep-vein thrombosis (DVT) was based on clinical suspicion and confirmed on Doppler ultrasound. The rate of asymptomatic DVT was not known. Those undergoing surgery for neoplastic disease or revision TKR and those unable to provide informed consent were excluded. Data was collected prospectively and entered into a dedicated database for analysis. Pre-operative data including age, gender, type of surgery, height, weight, co-morbidities, Charnley classification, ${ }^{14}$ functional assessment and the QoL were collected at pre- 
admission examination which occurred within four weeks of surgery. In-patient data including length of stay, complications, and destination after discharge, collected during the admission, and information at the 12-month follow-up was obtained at the orthopaedic outpatient review. Further functional and QoL assessment and measurement of height and weight were undertaken at 12 months.

The SF-12 and IKS questionnaires were posted to patients with instructions to complete them and bring them to their review. The objective components of the IKS were completed by the attending orthopaedic consultant or registrar. Patients who did not bring the questionnaire were subsequently contacted by a health professional independent of the study and the form was completed by telephone. This person was blinded to the patient's height and weight. Adverse events included the following: i) death related to the original procedure; ii) peri-operative medical or surgical complications; iii) post-operative medical or surgical complications resulting in a delay in discharge; iv) problems with wound healing; v) infection of the wound or joint using the Centres for Disease Control definitions ${ }^{15}$; and vi) an unplanned procedure and/or re-admission in the first 12 months after TKR. Deaths in the first 12 months clearly unrelated to the TKR were censored at the date of death.

The same two sets of scales, one in each clinic, were used throughout the study and were calibrated to ensure that they remained concordant at each weighing. Functional assessment was monitored using the International Knee Score (IKS). ${ }^{16}$ The QoL was assessed using the Short-Form 12 (SF-12) score, a validated measure of the QoL in joint replacement. ${ }^{17,18}$

We used the BMI to evaluate obesity. The definitions of the World Health Organisation were used. ${ }^{19}$ Thus a BMI of $<30 \mathrm{~kg} / \mathrm{m}^{2}$ was considered to be non-obese, of $30 \mathrm{~kg} \mathrm{~m}^{2}$ to $39 \mathrm{~kg} / \mathrm{m}^{2}$ as obese and ${ }^{3}$ than $40 \mathrm{~kg} / \mathrm{m}^{2}$ as morbidly obese.

A change of $\pm 5 \%$ of a patient's pre-operative weight was considered to be clinically significant. The United States Food and Drug Administration defines clinically significant weight loss as $5 \%$ or more of the baseline weight. ${ }^{20}$ A $5 \%$ weight loss in overweight patients has been shown to be the minimum weight loss required to induce metabolic and cardiovascular health benefits. ${ }^{12,21}$

A total of 573 primary TKRs in 533 patients was performed during the period of study. Three patients were excluded since they were unable to provide informed consent for cognitive (two) and logistical issues (one). We excluded one further patient who had undergone laparoscopic adjustable gastric banding eight weeks before surgery. All the remaining 529 patients were recruited to the study. There were no simultaneous bilateral procedures performed during the study period. A total of 40 patients underwent staged bilateral TKR and in these only the second procedure was included in the study analysis.

Of the 529 patients, 365 were women and 164 men with a median age of 71 years (interquartile range (IQR) 65 to 77 ) and a median BMI of $31.3 \mathrm{~kg} / \mathrm{m}^{2}$ (IQR 27.5 to 35.8 ).
The right knee was involved in 301. Of the total group 211 $(40 \%)$ were non-obese, $261(49 \%)$ were obese and $57(11 \%)$ were morbidly obese. The obese groups were more often female, were significantly younger than the nonobese patients and had a higher incidence of cardiovascular co-morbidities and diabetes (Table I).

Statistical analysis. The groups of patients who were nonobese, obese or morbidly obese pre-operatively were analysed for differences in functional and QoL outcomes and adverse events. Patients were also grouped according to weight loss or gain at 12 months for comparison. The data were analysed using SigmaPlot 11 software (Systat Software Inc., Chicago, Illinois). A p-value $\leq 0.05$ was considered to be significant. Function, QoL and weight change for BMI groups were compared in a univariate analysis using the rank-sum test. Differences in the groups were expressed using the median and the IQR. Weight-change groups were compared in a univariate analysis using the chi-squared test for categorical data and the rank-sum test for numerical variables. Logistic regression analysis adjusting for age and gender was used to derive the odds ratio (OR) with its $95 \%$ confidence interval (CI) associated with increasing BMI and the occurrence of an adverse event.

Sample-size calculation. This was based on the primary outcome of weight change 12 months after surgery. With an alpha value (two-sided) of $0.05,63$ patients in each group were required to provide $80 \%$ power to detect a difference of $2.5 \mathrm{~kg}$ (SD 5.0) in the mean weight between any two groups.

\section{Results}

There were four deaths before the follow-up at 12 months and four patients did not complete the questionnaires at 12 months. Therefore, 521 patients completed the assessment of function and QoL.

Weight change. There was no difference in the median weight change between the non-obese and obese groups at 12 months after surgery: non-obese $0.0 \mathrm{~kg}$ (IQR -2.0 to +3.0 ), obese $0.0 \mathrm{~kg}$ (IQR -1.0 to +3.0 ) and morbidly obese $0.0 \mathrm{~kg}$ (IQR (-3.0 to +3.0) (Kruskal-Wallis one way analysis of variance on ranks $p=0.739)$. Using $5 \%$ change from the pre-operative weight as the cut-off point, 73 patients $(14 \%)$ lost weight, $340(65 \%)$ remained unchanged and 108 $(21 \%)$ gained weight 12 months after surgery.

A total of $40(12.6 \%)$ of the patients classified as obese and morbidly obese lost weight at 12 months. Increasing age was significantly associated with weight loss at 12 months (Table II). The patients who gained weight at 12 months ( $\mathrm{n}=107$ ) had a slightly better improvement in functional score at 12 months (Table III). Weight loss or gain could not be predicted by any other pre-morbid characteristic or by improvements in function and physical health.

Functional and QoL outcomes. The median IKS score at 12 months improved in all weight groups, but was lower in obese compared with non-obese patients. There was a tenpoint difference in the median IKS change between non- 
Table I. Clinical and operative details in the 529 patients

\begin{tabular}{|c|c|c|c|c|}
\hline Variable & Non-obese $(\mathrm{n}=\mathbf{2 1 1})$ & Obese $(n=261)$ & Morbidly obese ( $n=57$ ) & p-value (chi-squared test) \\
\hline Median $\left(\mathrm{IQR}^{*}\right)$ BMI† $\left(\mathrm{kg} / \mathrm{m}^{2}\right)$ & 27 (25 to 29$)$ & 34 (32 to 36$)$ & 42 (41 to 45$)$ & \\
\hline Median (IQR) age (yrs) & 74 (68 to 79$)$ & $70(64$ to 76$)$ & 68 (61 to 73$)$ & $<0.001$ \\
\hline \multicolumn{5}{|l|}{ Gender (\%) } \\
\hline Male & $84(51)$ & $68(42)$ & $12(7)$ & 0.001 \\
\hline Female & $127(35)$ & $193(53)$ & $45(12)$ & \\
\hline \multicolumn{5}{|l|}{ Aetiology $\ddagger$} \\
\hline OA & $193(39)$ & $249(50)$ & $55(11)$ & 0.142 \\
\hline RA & $18(56)$ & $12(38)$ & $2(6)$ & \\
\hline \multicolumn{5}{|l|}{ Charnley class (\%) } \\
\hline A & $181(40)$ & $226(49)$ & $52(11)$ & 0.308 \\
\hline $\mathrm{B}$ & $12(32)$ & $22(60)$ & $3(8)$ & \\
\hline $\mathrm{C}$ & $18(55)$ & $13(39)$ & $2(6)$ & \\
\hline Co-morbidities (range) & $3(2$ to 4$)$ & $3(2$ to 4$)$ & $3(2$ to 4$)$ & 0.642 \\
\hline Cardiovascular disease (\%) & $144(68.2)$ & $198(75.8)$ & $49(86.0)$ & 0.016 \\
\hline Diabetes (\%) & $31(14.7)$ & $61(23.4)$ & $14(24.6)$ & 0.043 \\
\hline Gastrointestinal disorder (\%) & $60(28.4)$ & $74(28.3)$ & $18(31.6)$ & 0.881 \\
\hline Haematological disorders (\%) & $9(4.3)$ & $11(4.2)$ & $3(5.3)$ & 0.936 \\
\hline Oncological disease (\%) & $12(5.7)$ & $18(6.9)$ & $1(1.8)$ & 0.323 \\
\hline Respiratory disease (\%) & $33(15.6)$ & $46(17.6)$ & $15(26.3)$ & 0.173 \\
\hline \multicolumn{5}{|l|}{ Type of prosthesis ${ }^{\S}(\%)$} \\
\hline $\mathrm{CR}$ & $88(40)$ & $106(48)$ & $25(11)$ & 0.932 \\
\hline PS & $119(40)$ & $148(50)$ & $30(10)$ & \\
\hline UC & $4(31)$ & $7(54)$ & $2(15)$ & \\
\hline \multicolumn{5}{|l|}{ Patellar resurfacing (\%) } \\
\hline Yes & $79(45)$ & 77 (44) & $20(11)$ & 0.182 \\
\hline No & $132(37)$ & $184(52)$ & $11(10)$ & \\
\hline Length of stay in days (range) & 5 (5 to 6$)$ & $5(5$ to 6$)$ & $5(5$ to 6$)$ & 0.507 \\
\hline \multicolumn{5}{|l|}{ Discharge destination (\%) } \\
\hline Home & $164(39)$ & $213(51)$ & $41(10)$ & 0.223 \\
\hline Rehabilitation & $47(42)$ & $48(43)$ & $16(14)$ & \\
\hline \multicolumn{5}{|l|}{ * IQR, interquartile range } \\
\hline \multicolumn{5}{|c|}{ † BMI, body mass index } \\
\hline \multicolumn{5}{|c|}{ ‡ OA, osteoarthritis; RA, rheumatoid arthritis } \\
\hline$\S C R$, cruciate-retaining; PS, po & terior-stabilising; UC, & Itra-congruent & & \\
\hline
\end{tabular}

obese (71, IQR, 47 to 92), obese (60, IQR 39 to 87) and morbidly obese patients (61, IQR 39 to 81 ) (Table IV). The change in the functional score of the IKS in particular was poorer for obese and morbidly obese patients compared with non-obese patients. There was no significant difference in the change in the median knee score component of the IKS (Kruskal-Wallis $\mathrm{p}=0.45$ ) but there was a difference in the median score for pain at 12 months: non-obese (45, IQR 30 to 50), obese (45, IQR 20 to 45) and morbidly obese (40, IQR 20 to 45, Kruskal-Wallis $\mathrm{p}=0.021$ ).

There was no statistical difference in the median preoperative SF-12 physical- or mental-health component scores between the non-obese and obese patients. At 12 months, the physical component score improved to a significantly greater degree (Kruskal-Wallis $\mathrm{p}=0.05$ ) in non-obese and obese compared with morbidly obese patients. There was no significant difference in the median mental component score in any weight group (Table V).

Adverse events. These are recorded in Table VI. An adverse event occurred in $20(35.1 \%)$ of the morbidly obese patients compared with $59(22.1 \%)$ in obese and $30(14.2 \%)$ in non-obese patients (chi-squared $\mathrm{p}=0.001)$. A higher re-admission rate was also observed in the obese groups. The rate of prosthetic infection and DVT was also significantly higher in obese and morbidly obese patients (Table VI).

Using the BMI as a continuous variable the OR for the risk of an adverse event was 1.084 (95\% CI 1.043 to 1.126) for every unit increase in BMI, adjusted for age and gender. Potential confounding factors. The presence of both cardiovascular co-morbidities and diabetes was significantly higher in the obese groups (Table I). These 
Table II. Variables (median interquartile range when appropriate) tested for an association with weight loss

\begin{tabular}{|c|c|c|c|}
\hline Variable & $\geq 5 \%$ weight loss $(n=40)$ & No weight loss $(n=274)$ & p-value \\
\hline Age (yrs) & 74 (68 to 77$)$ & 69 (62 to 75$)$ & 0.008 \\
\hline \multicolumn{4}{|l|}{ Gender } \\
\hline Male & 8 & 71 & 0.542 \\
\hline Female & 32 & 203 & \\
\hline \multicolumn{4}{|l|}{ Aetiology } \\
\hline Osteoarthritis & 39 & 262 & 0.895 \\
\hline Rheumatoid arthritis & 1 & 12 & \\
\hline \multicolumn{4}{|l|}{ Charnley class } \\
\hline $\mathrm{A}$ & 34 & 242 & 0.466 \\
\hline $\mathrm{B}$ & 5 & 20 & \\
\hline $\mathrm{C}$ & 1 & 12 & \\
\hline Co-morbidities (range) & 3 (2 to 4$)$ & 3 (2 to 4$)$ & 0.988 \\
\hline \multicolumn{4}{|l|}{ Diabetes } \\
\hline Yes & 8 & 66 & 0.712 \\
\hline No & 32 & 208 & \\
\hline \multicolumn{4}{|l|}{ Cardiovascular disease } \\
\hline Yes & 33 & 209 & 0.501 \\
\hline No & 7 & 65 & \\
\hline \multicolumn{4}{|l|}{ Respiratory disease } \\
\hline Yes & 8 & 52 & 0.951 \\
\hline No & 32 & 222 & \\
\hline Pre-operative IKS* (range) & 35 (26 to 43 ) & 31 (23 to 39$)$ & 0.184 \\
\hline Function & 38 (20 to 50$)$ & 35 (24 to 50$)$ & 0.965 \\
\hline Total & 69 (53 to 86$)$ & 69 (55 to 85$)$ & 0.796 \\
\hline \multicolumn{4}{|l|}{ Pre-operative SF- $12^{\dagger}$ (range) } \\
\hline $\mathrm{PCS}^{\ddagger}$ & 23.4 (21.2 to 25.5$)$ & $25.4(22.3$ to 29.1$)$ & 0.002 \\
\hline $\mathrm{MCS}^{\S}$ & 52.2 (42.4 to 59.3 ) & $52.1(42.4$ to 58.8$)$ & 0.782 \\
\hline \multicolumn{4}{|l|}{ IKS at 12 months (range) } \\
\hline Knee & 80 (71 to 86$)$ & 80 (60 to 90$)$ & 0.829 \\
\hline Function & 50 (35 to 65$)$ & 50 (40 to 70$)$ & 0.268 \\
\hline Total & 127 (104 to 146$)$ & 131 (105 to 155$)$ & 0.650 \\
\hline \multicolumn{4}{|l|}{ SF-12 at 12 months (range) } \\
\hline PCS & 32.4 (29.1 to 39.5$)$ & 36.3 (17.1 to 46.3 ) & 0.306 \\
\hline MCS & 48.7 (40.3 to 56.5 ) & 52.5 (41.6 to 59.9$)$ & 0.132 \\
\hline \multicolumn{4}{|l|}{ IKS change (range) } \\
\hline Knee & 47 (34 to 57$)$ & 44 (27 to 61$)$ & 0.967 \\
\hline Function & $10(-4$ to 35$)$ & $15(0$ to 30$)$ & 0.364 \\
\hline Total & 52 (41 to 80$)$ & 61 (38 to 87 ) & 0.545 \\
\hline \multicolumn{4}{|l|}{ SF-12 change (range) } \\
\hline PCS & 10.1 (4.8 to 16.2 ) & 9.3 (2.5 to 18.6$)$ & 0.609 \\
\hline MCS & $-2.0(-11.5$ to 7.4$)$ & $0.3(-7.6$ to 7.9$)$ & 0.208 \\
\hline
\end{tabular}

* IKS, international knee score

† SF-12. short-form 12

‡ PCS, physical component score

$\S$ MCS, mental component score

II categorical variables, chi-squared test; numerical variables, Mann-Whitney rank sum test

variables were individually analysed to determine if any were associated with the rate of adverse events. There was no difference in the rate of cardiovascular comorbidities (chi-squared $\mathrm{p}=0.636$ ) or diabetes (chisquared $\mathrm{p}=0.475$ ) in patients who had an adverse event compared with those who did not.

\section{Discussion}

The incidence of obesity in the series was $60 \%$, and of more importance, that of morbid obesity was $11 \%$. Obese patients who underwent TKR were a mean of four years younger and morbidly obese patients were a mean of six years younger than non-obese patients. Our findings are 
Table III. Variables (median interquartile range when appropriate) tested for an association with weight gain

\begin{tabular}{|c|c|c|c|}
\hline Variable & $\geq 5 \%$ weight gain $(n=107)$ & No weight gain ( $n=414$ ) & p-value \\
\hline Age (yrs) & $70(65$ to 76$)$ & 71 (65 to 77$)$ & 0.281 \\
\hline \multicolumn{4}{|l|}{ Gender } \\
\hline Male & 29 & 132 & \multirow[t]{2}{*}{0.403} \\
\hline Female & 78 & 282 & \\
\hline \multicolumn{4}{|l|}{ Aetiology } \\
\hline Osteoarthritis & 99 & 393 & \multirow[t]{2}{*}{0.465} \\
\hline Rheumatoid arthritis & 8 & 21 & \\
\hline \multicolumn{4}{|l|}{ Charnley class } \\
\hline A & 87 & 367 & \multirow[t]{3}{*}{0.130} \\
\hline B & 11 & 26 & \\
\hline C & 19 & 21 & \\
\hline Co-morbidities (range) & $2(2$ to 4$)$ & $3(2$ to 4$)$ & 0.254 \\
\hline \multicolumn{4}{|l|}{ Diabetes } \\
\hline Yes & 17 & 87 & \multirow[t]{2}{*}{0.295} \\
\hline No & 90 & 327 & \\
\hline \multicolumn{4}{|l|}{ Cardiovascular disease } \\
\hline Yes & 88 & 299 & \multirow[t]{2}{*}{0.165} \\
\hline No & 22 & 115 & \\
\hline \multicolumn{4}{|l|}{ Respiratory disease } \\
\hline Yes & 12 & 80 & \multirow[t]{2}{*}{0.069} \\
\hline No & 95 & 334 & \\
\hline Pre-operative IKS* (range) & $29(25$ to 40$)$ & 32 (25 to 40$)$ & 0.432 \\
\hline Function & 35 (20 to 50$)$ & $35(30$ to 50$)$ & 0.068 \\
\hline Total & 67 (53 to 79$)$ & 71 (57 to 87$)$ & 0.139 \\
\hline \multicolumn{4}{|l|}{ Pre-operative SF-12† (range) } \\
\hline $\mathrm{PCS}^{\ddagger}$ & 25.1 (22.6 to 29.7$)$ & $25.3(22.2$ to 28.8$)$ & 0.688 \\
\hline $\mathrm{MCS}^{\S}$ & $52.1(40.1$ to 58.7$)$ & 52.7 (44.0 to 58.7$)$ & 0.199 \\
\hline \multicolumn{4}{|l|}{ IKS at 12 months (range) } \\
\hline Knee & $83(65$ to 91$)$ & $82(63$ to 91$)$ & 0.716 \\
\hline Function & 60 (45 to 80$)$ & 55 (40 to 80$)$ & 0.348 \\
\hline Total & 136 (113 to 172 ) & 134 (109 to 162 ) & 0.543 \\
\hline \multicolumn{4}{|l|}{ SF-12 at 12 months (range) } \\
\hline PCS & 37.1 (28.3 to 47.6$)$ & $35.6(28.2$ to 44.6$)$ & 0.215 \\
\hline MCS & $54.0(42.0$ to 59.4$)$ & 52.5 (42.1 to 59.9$)$ & 0.952 \\
\hline \multicolumn{4}{|l|}{ IKS change (range) } \\
\hline Knee & 49 (30 to 61$)$ & 46 (30 to 59$)$ & 0.412 \\
\hline Function & $25(10$ to 40$)$ & 20 (4 to 35$)$ & 0.011 \\
\hline Total & 70 (46 to 95$)$ & 64 (40 to 88$)$ & 0.088 \\
\hline \multicolumn{4}{|l|}{ SF-12 change (range) } \\
\hline PCS & $12.3(4.0$ to 20.7$)$ & $9.0(2.7$ to 18.1$)$ & 0.174 \\
\hline MCS & 2.5 ( -6.5 to 9.6$)$ & $0.0(-7.6$ to 7.2$)$ & 0.091 \\
\hline \multicolumn{4}{|c|}{ * IKS, international knee score } \\
\hline \multicolumn{4}{|c|}{ † SF-12, short-form 12} \\
\hline \multicolumn{4}{|c|}{ ‡ PCS, physical component score } \\
\hline \multicolumn{4}{|c|}{$\S \mathrm{MCS}$, mental component score } \\
\hline
\end{tabular}

similar to those of others, ${ }^{22}$ and younger obese and morbidly obese patients are likely to add to the challenge of joint replacement in the future. An association between obesity and early prosthetic failure in primary TKR has been shown in some studies ${ }^{5,23,24}$ but not in others. ${ }^{25,26}$ With a population that is ageing and becoming more overweight, a rapid increase in the rate of revision TKR remains a possibility and continued follow-up of large series is required.

Loss of weight of between $5 \%$ and $15 \%$ produces significant improvements in cardiovascular and metabolic health and weight loss of $10 \%$ over six to 12 months is seen as a realistic goal for individuals trying to lose weight. ${ }^{18,27}$ Although weight loss has been reported to occur in some 
Table IV. Median (interquartile range) International Knee Score in the three groups

\begin{tabular}{|c|c|c|c|c|}
\hline & Non-obese & Obese & Morbidly obese & p-value ${ }^{*}$ \\
\hline \multicolumn{5}{|c|}{ Pre-operative (range) } \\
\hline Knee & 32 (25 to 41$)$ & 32 (24 to 40$)$ & 28 (24 to 40$)$ & 0.329 \\
\hline Function & $40(30$ to 50$)$ & 35 (30 to 50$)$ & 35 (20 to 48 ) & 0.116 \\
\hline Total & 72 (58 to 89$)$ & 70 (55 to 85$)$ & 65 (45 to 86 ) & 0.103 \\
\hline \multicolumn{5}{|c|}{12 months (range) } \\
\hline Knee & $86(67$ to 92$)$ & 80 (61 to 90$)$ & 76 (62 to 88$)$ & 0.006 \\
\hline Function & $60(45$ to 80$)$ & 50 (40 to 78$)$ & 50 (35 to 65$)$ & $<0.001$ \\
\hline Total & $142(122$ to 173$)$ & 133 (106 to 159$)$ & 126 (96 to 149$)$ & $<0.001$ \\
\hline \multicolumn{5}{|c|}{ Change (range) } \\
\hline Knee & 49 (32 to 59$)$ & 45 (28 to 62$)$ & 44 (23 to 59$)$ & 0.450 \\
\hline Function & 25 (10 to 35$)$ & $15(0$ to 35$)$ & $15(0$ to 30$)$ & 0.002 \\
\hline Total & 71 (47 to 92 ) & 60 (39 to 87$)$ & 61 (39 to 81 ) & 0.016 \\
\hline
\end{tabular}

* Kruskal-Wallis one-way analysis of variance on ranks test

Table V. Median (interquartile range) SF-12 physical component score (PCS) and mental component score (MCS) score in the three groups

\begin{tabular}{|c|c|c|c|c|}
\hline & Non-obese & Obese & Morbidly obese & p-value ${ }^{*}$ \\
\hline \multicolumn{5}{|l|}{ PCS (range) } \\
\hline Pre-operative & 25.41 (22.42 to 29.82$)$ & 25.10 (22.06 to 28.77$)$ & 25.07 (22.54 to 28.29 ) & 0.331 \\
\hline 12 months & 35.84 (29.41 to 45.31$)$ & $36.30(28.05$ to 45.80$)$ & 31.11 (25.82 to 42.21$)$ & 0.050 \\
\hline Change & 9.47 (3.24 to 18.84$)$ & 9.93 (2.98 to 18.25$)$ & 5.32 (1.52 to 18.48$)$ & 0.294 \\
\hline \multicolumn{5}{|l|}{ MCS (range) } \\
\hline Pre-operative & 53.51 (43.56 to 58.51$)$ & 52.08 (42.53 to 58.92 ) & 52.11 (40.84 to 56.96$)$ & 0.535 \\
\hline 12 months & 52.80 (42.20 to 59.87$)$ & 52.07 (40.81 to 59.35 ) & 56.69 (44.04 to 60.98 ) & 0.347 \\
\hline Change & $0.65(-7.81$ to +7.47$)$ & $0.40(-7.71$ to +6.96$)$ & $3.29(-4.85$ to +11.82$)$ & 0.100 \\
\hline
\end{tabular}

patients after TKR, ${ }^{28}$ with the exception of one study, ${ }^{12}$ weight loss has been based on any level of change from baseline weight, irrespective of the amount lost. For example, a change of as little as $1 \mathrm{~kg}$ over one year has been classified as weight loss. There was a higher incidence of weight gain, compared with weight loss in our study and similar findings have been reported by others two years after primary TKR. ${ }^{12}$

The only clinically significant predictor of weight loss 12 months after primary TKR was age. Weight loss tended to occur more commonly in older patients. Weight loss or gain could not be predicted by any other patient pre-morbid characteristic or the functional or QoL score, and did not correlate with improvements in function and QoL 12 months after surgery. Multiple medical comorbidities and generalised arthropathy have been perceived as potential barriers to activity-related weight loss after TKR and based on these beliefs these patients have been excluded from previous studies. ${ }^{29,30}$ In our study the level of disability had no influence on weight loss. This is contrary to expectations, since healthier patients would be predicted to have a greater physical activity level and therefore would be more likely to lose weight. However, in the absence of modification of calorie intake, participa- tion in regular exercise does not lead to significant weight loss in overweight individuals. ${ }^{27,31}$

Obese and morbidly obese patients had a poorer functional result from TKR than did non-obese patients. There is wide variation in the literature regarding the impact of obesity on the functional outcome after TKR. A poorer outcome has been reported in obese patients, ${ }^{24,26}$ and to a greater degree in morbidly obese patients. ${ }^{32-34}$ Some studies have suggested that there are no or only minor differences between obese and non-obese patients, with comparable levels of improvement. ${ }^{35,36}$ However, results should be treated with caution when studies have used datasets which exclude up to $75 \%$ of patients because of lack of complete data. ${ }^{35,36}$ The level of follow-up can be a limiting factor. ${ }^{37}$ Patients who do not respond to health questionnaires more often have a poorer functional outcome ${ }^{38}$ and are more dissatisfied with the result of joint replacement. ${ }^{39}$ Without complete patient representation and follow-up, nonresponder bias may limit the interpretation of any findings.

Poorer pain scores may contribute to the poorer functional results expressed by obese and morbidly obese patients compared with non-obese patients. However, obesity is a complex issue and therefore it is likely that improvement in the level of physical activity after TKR in 
Table VI. Complications in the first 12 months after primary total knee replacement

\begin{tabular}{|c|c|c|c|c|}
\hline Event & Non-obese & Obese & Morbidly obese & p-value \\
\hline Acute myocardial infarct ${ }^{*}$ & 4 & 2 & 0 & 0.357 \\
\hline Acute pulmonary oedema ${ }^{*}$ & 0 & 2 & 0 & 0.357 \\
\hline Acute renal failure ${ }^{*}$ & 0 & 2 & 0 & 0.357 \\
\hline Bowel obstruction ${ }^{*}$ & 1 & 1 & 0 & 0.875 \\
\hline Cerebrovascular accident ${ }^{*}$ & 1 & 0 & 0 & 0.470 \\
\hline Deceased within 12 months & 2 & 2 & 0 & 0.764 \\
\hline Deep-vein thrombosis ${ }^{*}$ & 1 & 3 & 3 & 0.018 \\
\hline Delirium ${ }^{*}$ & 7 & 4 & 0 & 0.204 \\
\hline Electrolyte imbalance $e^{* \ddagger}$ & 1 & 0 & 0 & 0.470 \\
\hline $\begin{array}{l}\text { Femoral malalignment }{ }^{\dagger} \text { (post-operative coronal } \\
\text { alignment on full-length weight-bearing radiograph- } \\
\text { valgus } 11^{\circ} \text { ) }\end{array}$ & 0 & 1 & 0 & 0.598 \\
\hline Intra-operative fracture ${ }^{\dagger}$ & 1 & 3 & 0 & 0.550 \\
\hline Joint infection $^{\dagger}$ & 1 & 4 & 3 & 0.031 \\
\hline Pain and locking ${ }^{\dagger \S}$ & 0 & 0 & 1 & 0.016 \\
\hline $\begin{array}{l}\text { Patellar resurfacing }{ }^{\dagger \S} \text { (primary resurfacing within } \\
\text { the first } 12 \text { months of index survey) }\end{array}$ & 0 & 1 & 1 & 0.160 \\
\hline Poor range of movement ${ }^{\dagger \S}$ (flexion less than $90^{\circ}$ ) & 4 & 8 & 2 & 0.372 \\
\hline Pulmonary embolus ${ }^{*}$ & 2 & 3 & 0 & 0.716 \\
\hline Respiratory-track infection* & 2 & 2 & 0 & 0.764 \\
\hline Respiratory depression ${ }^{*}$ & 0 & 1 & 0 & 0.598 \\
\hline Ruptured patella tendon ${ }^{\dagger \S}$ & 0 & 1 & 0 & 0.598 \\
\hline Ruptured quadriceps ${ }^{*} \uparrow$ & 1 & 1 & 0 & 0.875 \\
\hline Ventricular tachycardia ${ }^{\dagger \S}$ & 0 & 1 & 1 & 0.160 \\
\hline Unstable knee ${ }^{\dagger \S}$ & 0 & 1 & 0 & 0.598 \\
\hline Urinary retention* & 1 & 1 & 1 & 0.446 \\
\hline Wound complications (superficial) ${ }^{\dagger}(\%)$ & $6(2.8)$ & $18(6.7)$ & $9(15.7)$ & 0.001 \\
\hline Total surgical complications (\%) & $13(6.2)$ & $38(14.2)$ & $15(26.3)$ & $<0.001$ \\
\hline Total medical complications (\%) & $19(9.0)$ & $22(8.2)$ & $5(9.8)$ & 0.973 \\
\hline Unplanned readmissions (\%) & $10(4.7)$ & $29(10.6)$ & $13(22.8)$ & $<0.001$ \\
\hline Total adverse events (\%) & $30(14.2)$ & $59(22.1)$ & $20(35.1)$ & 0.001 \\
\hline \multicolumn{5}{|l|}{$\begin{array}{l}\text { * medical complication } \\
\text { † surgical complication } \\
\text { † intensive care admissior }\end{array}$} \\
\hline $\begin{array}{l}\S \text { re-operation. One death occurred as a result of a cor } \\
\text { deaths resulted from causes unrelated to total knee re } \\
\text { mia in one, prostate cancer in one, bladder cancer in } \\
\text { an adverse event }\end{array}$ & $\begin{array}{l}\text { event withi } \\
\text { ement but oc } \\
\text { hese patient }\end{array}$ & $\begin{array}{l}\text { eks of surg } \\
\text { vithin } 12 \mathrm{~m} \\
\text { ensored a }\end{array}$ & $\begin{array}{l}\text { as included as an } \\
\text { urgery (complica } \\
\text { f death, but were }\end{array}$ & $\begin{array}{l}\text { All other } \\
\text { f; leukae- } \\
\text { unted as }\end{array}$ \\
\hline
\end{tabular}

obese patients requires a comprehensive approach involving behavioural modification and longer term practitioner support. ${ }^{27}$ Current physiotherapy programmes offered after joint replacement are short-term and aim to restore function and mobility. Adaptation of these routines to provide a more comprehensive approach, such as that established for cardiac rehabilitation, warrants consideration. ${ }^{40}$

Despite comparable SF-12 physical health scores before surgery, these were significantly lower in morbidly obese patients at 12 months after surgery. Only one other study has examined the QoL outcome after TKR specifically in morbidly obese patients using the SF- $12 .{ }^{36}$ In that study the SF-12 physical component score was significantly lower in morbidly obese compared with non-morbidly obese patients both pre-operatively and at 12 months after surgery. However, there was no difference in the change in the SF-12 physical component score between morbidly obese and non-morbidly obese patients and therefore the authors reported that morbidly obese patients had the same benefit after TKR as all other patients.
The incidence of adverse effects within the first 12 months after primary TKR was $35.1 \%$ for morbidly obese patients compared with $22.1 \%$ in obese patients and $14.2 \%$ in non-obese patients. Surgical complications were significantly higher in obese and morbidly obese patients and this may be reflection of technical difficulty. ${ }^{41}$ Significantly higher peri-operative and post-operative complications have been reported in obese patients undergoing TKR. ${ }^{32,42}$ We have shown that for each unit increase in the BMI the risk of incurring an adverse event increased by $8 \%$, even after adjustment for age and gender. In particular, we noted a higher rate of prosthetic infection and symptomatic DVT in obese patients, consistent with previous reports. ${ }^{43-}$ ${ }^{45}$ However, in a recent study it was found that obesity did not confer a higher risk of DVT if patients participated in an early mobilisation programme. ${ }^{46}$ We also note that in our study a diagnosis of DVT was initially based on clinical suspicion and subsequently confirmed on Doppler ultrasound and the rate of asymptomatic DVT was not known.

The results of our study implicate obesity as a modulator or a negative outcome in primary TKR. Of concern, one in 
five patients gained $5 \%$ or more of the pre-operative weight within 12 months of TKR. By contrast, a smaller percentage of obese patients lost the minimum amount of weight to be considered clinically significant and, aside from an association with advancing age, weight loss could not be predicted. Obese patients should be counselled about a poorer functional outcome after TKR as well as the risk of weight gain and a higher risk of adverse events in the first 12 months after surgery. A multitude of complications was recorded in morbidly obese patients in particular and their eligibility for TKR without previous weight loss warrants further consideration.

We wish to thank E. Nemiro and C. Howley for assisting with the collection of data and recording the anthropomorphic measurements and acknowledge that Dr M. M. Dowsey holds an NHMRC post-graduate scholarship in Public Health (ID number 502021).

No benefits in any form have been received or will be received from a commercial party related directly or indirectly to the subject of this article.

\section{References}

1. Fehring TK, Odum SM, Griffin WL, Mason JB, McCoy TH. The obesity epidemic: its effect on total joint arthroplasty. J Arthroplasty 2007;22(Suppl 2):71-6.

2. De Guia N, Zhu N, Keresteci M, Shi JE. Obesity and joint replacement surgery in Canada: findings from the Canadian Joint Replacement Registry (CJRR). Health Policy 2006;1:36-43

3. Liu B, Balkwill A, Banks E, et al. Relationship of height, weight and body mass index to the risk of hip and knee replacements in middle-aged women. Rheumatology (Oxford) 2007;46:861-7

4. Dowsey MM, Choong PF. Early outcomes and complications following joint arthroplasty in obese patients: a review of the published reports. ANZ J Surg 2008;78:43944.

5. Berend ME, Ritter MA, Meding JB, et al. Tibial component failure mechanisms in total knee arthroplasty. Clin Orthop 2004;428:26-34.

6. Fitzgerald JD, Orav EJ, Lee TH, et al. Patient quality of life during the 12 months following joint replacement surgery. Arthritis Rheum 2004;51:100-9.

7. Jones CA, Beaupre LA, Johnston DW, Suarez-AImazor ME. Total joint arthroplasties: current concepts of patient outcomes after surgery. Rheum Dis Clin North Am 2007;33:71-86

8. Orbell S, Espley A, Johnston M, Rowley D. Health benefits of joint replacement surgery for patients with osteoarthritis: prospective evaluation using independent assessments in Scotland. J Epidemiol Community Health 1998;52:564-70.

9. Shields RK, Enloe LJ, Leo KC. Health related quality of life in patients with total hip or knee replacement. Arch Phys Med Rehabil 1999;80:572-9.

10. Heisel C, Silva M, dela Rosa MA, Schmalzried TP. The effects of lower-extremity total joint replacement for arthritis on obesity. Orthopedics 2005;28:157-9.

11. Donovan J, Dingwall I, McChesney S. Weight change 1 year following total knee or hip arthroplasty. ANZ J Surg 2006;76:222-5.

12. Lachiewicz AM, Lachiewicz PF. Weight and activity change in overweight and obese patients after primary total knee arthroplasty. J Arthroplasty 2008;23:33-40.

13. Dowsey MM, Kilgour ML, Santamaria MM, Choong PF. Clinical pathways in hip and knee arthroplasty: a prospective randomised controlled study. Med J Aust 1999;170:61-76.

14. Charnley J. The long-term results of low-friction arthroplasty of the hip performed as a primary intervention. J Bone Joint Surg [Br] 1972;54-B:61-76.

15. Mangram AJ, Horan TC, Pearson ML, Silver LC, Jarvis WR. Guideline for prevention of surgial site infection, 1999: Hospital Infection Control Practices Advisory Committee. Infect Control Hosp Epidemiol 1999;20:250-78.

16. Pollard B, Johnston M, Dieppe P. What do osteoarthritis health outcome instruments measure?: impairment, activity limitation, or participation restriction? J Rheumato/ 2006;33:757-63

17. Dunbar MJ, Robertsson O, Ryd L, Lidgren L. Appropriate questionnaires for knee arthroplasty: results of a survey of 3600 patients from The Swedish Knee Arthroplasty Registry. J Bone Joint Surg [Br] 2001;83-B:339-44.

18. Gandek B, Ware JE, Aaronson NK, et al. Cross-validation of item selection and scoring for the SF-12 Heath Survey in nine countries: results from the I00LA Project: International Quality of Life Assessment. J Clin Epidemiol 1998;51:1171-8.
19. No authors listed. World Health Organization: obesity and overweight. 2005. http:/ /www.infobase.who.int (date last accessed 31 December 2007).

20. No authors listed. US Food and Drug Administration Center for Drug Evaluation and Research Guidance for Industry: developing productions for weight management http://www.fda.gov/downloads/Drugs/GuidanceComplianceRegulatorylnformation/ Guidances 2007 (date last accessed 31 July 2009).

21. No authors listed. Dietitians Association of Australia. Best practice guidelines for the treatment of overweight and obesity in adults. 2005. http://www.daa.asn.au/ (date last accessed 19 October 2009).

22. Changulani M, Kalairajah Y, Peel T, Field RE. The relationship between obesity and the age at which hip and knee replacement is undertaken. J Bone Joint Surg $[\mathrm{Br}]$ 2008:90-B:360-3.

23. Vazquez-Vela Johnson G, Worland RL, Keenan J, Norambuena N. Patient demographics as a predictor of the ten-year survival rate in primary total knee replacement. J Bone Joint Surg [Br] 2003;85-B:52-6.

24. Foran JR, Mont MA, Etienne G, Jones LC, Hungerford DS. The outcome of total knee arthroplasty in obese patients. J Bone Joint Surg [Am] 2004;86-A:1609-15.

25. Amin AK, Patton JT, Cook RE, Brenkel IJ. Does obesity influence the clinical outcome at five years following total knee replacement for osteoarthritis? J Bone Joint Surg [Br] 2006;88-B:335-40.

26. Jackson MP, Sexton SA, Walter WL, Walter WK, Zicat BA. The impact of obesity on the mid-term outcome of cementless total knee replacement. J Bone Joint Surg [Br] 2009;91-B:1044-8.

27. Wadden TA, Sarwer DB, Berkowitz RI. Behavioural treatment of the overweight patient. Baillieres Best Pract Res Clin Endocrinol Metab 1999;13:93-107.

28. Woodruff MJ, Stone MH. Comparison of weight changes after total hip or knee arthroplasty. J Arthroplasty 2001;16:22-4.

29. Meyer C, Roach R, Jain S. Weight change following total hip replacement: a comparison of obese and non-obese patients (letter). Surgeon 2006;4:390.

30. Jain SA, Roach RT, Travlos J. Changes in body mass index following primary elec tive total hip arthroplasty: correlation with outcome at 2 years. Acta Orthop Belg 2003;69:421-5.

31. National Health and Medical Research Council. Clinical practice guidelines for the management of overweight and obesity in adults. Canberra: National Health and Medical Research Council, 2003:95-118

32. Amin AK, Clayton RA, Patton JT. Total knee replacement in morbidly obese patients: results of a prospective, matched study. J Bone Joint Surg [Br] 2006;88B:1321-6.

33. Pritchett JW, Bortel DT. Knee replacement in morbidly obese women. Surg Gynecol Obstet 1991;173:119-22

34. Winiarsky R, Barth P, Lotke P. Total knee arthroplasty in morbidly obese patients J Bone Joint Surg [Am] 1998;80-A:1770-4.

35. Stickles B, Phillips L, Brox WT, Owens B, Lanzer WL. Definiting the relationship between obesity and total joint arthroplasty. Obes Res 2001;9:219-23.

36. Rajgopal V, Bourne RB, Chesworth BM, et al. The impact of morbid obesity on patient outcomes after total knee arthroplasty. J Arthroplasty 2008;23:795-800.

37. Spicer DD, Pomeroy DL, Badenhausen WE, et al. Body mass index as a predictor of outcome in total knee replacement. Int Orthop 2001;25:246-9.

38. Kim J, Lonner JH, Nelson CL, Lotke PA. Response bias: effect on outcomes evaluation by mail surveys after total knee arthroplasty. J Bone Joint Surg [Am]2004;86A:15-21

39. Robertsson 0, Dunbar MJ. Patient satisfaction compared with general health and disease-specific questionnaires in knee arthroplasty patients. J Arthroplasty 2001;16:476-82.

40. Lavie CJ, Thomas RJ, Squires RW, Allison TG, Milani RV. Exercise training and cardiac rehabilitation in primary and secondary prevention of coronary heart disease. Mayo Clin Proc 2009;84:373-83.

41. Guss D, Bhattacharyya T. Perioperative management of the obese orthopaedic patient. J Am Acad Orthop Surg 2006;14:425-32.

42. Miric A, Lim M, Kahn B, et al. Perioperative morbidity following total knee arthroplasty among obese patients. J Knee Surg 2002;15:77-83.

43. Patel VP, Walsh M, Sehgal B, et al. Factors associated with prolonged wound drainage after primary total hip and knee arthroplasty. J Bone Joint Surg [Am] 2007;89-A:33-8.

44. Dowsey MM, Choong PF. Obese diabetic patients are at substantial risk for deep infection after primary TKA. Clin Orthop 2008;467:1577-81.

45. White RH, Henderson MC. Risk factors for venous thromboembolism after total hip and knee replacement surgery. Curr Opin Pulm Med 2002;8:365-71.

46. Pearse EO, Caldwell BF, Lockwood RJ, Hollard J. Early mobilisation after conventional knee replacement may reduce the risk of postoperative venous thromboembolism. J Bone Joint Surg [Br] 2007;89-B:316-22. 